\title{
Lexis
}

Journal in English Lexicology

1 | 2008

Polysemy

\section{Taking a New Look at Lexical Networks}

\section{Gaëtanelle Gilquin}

\section{OpenEdition}

\section{Journals}

Electronic version

URL: http://journals.openedition.org/lexis/757

DOI: $10.4000 /$ lexis.757

ISSN: 1951-6215

\section{Publisher}

Université Jean Moulin - Lyon 3

\section{Electronic reference}

Gaëtanelle Gilquin, « Taking a New Look at Lexical Networks », Lexis [Online], 1 | 2008, Online since 04 July 2008, connection on 03 May 2019. URL : http://journals.openedition.org/lexis/757 ; DOI :

$10.4000 /$ lexis. 757

\section{(9) $(\mathcal{\Theta \Theta}$}

Lexis is licensed under a Creative Commons Attribution-NonCommercial-NoDerivatives 4.0

International License. 


\title{
Taking a New Look at Lexical Networks
}

Gaëtanelle Gilquin ${ }^{10}$

\section{Résumé}

Cet article a pour but d'étudier la validité empirique des réseaux lexicaux tels que décrits dans la littérature cognitive, qui rendent compte des différents sens d'un mot polysémique en montrant comment chaque sens est une extension d'un autre. Le point de départ est le réseau lexical décrit par Norvig \& Lakoff [1987] pour le verbe anglais take. L'article compare la structure de ce réseau avec des données issues de corpus et d'une expérience de production de phrase. L'évaluation de la validité du modèle de Norvig \& Lakoff est à la fois linguistique (le modèle reflète-t-il la fréquence telle qu'elle est attestée dans la langue ?) et cognitive (le modèle reflète-t-il la saillance dans l'esprit du locuteur ordinaire ?). Il est démontré que le modèle ne tient pas face à l'analyse empirique proposée ici, mais qu'il peut cependant avoir un rôle à jouer dans une théorie de la polysémie.

Mots-clés : polysémie - réseau lexical - validation empirique - corpus expérimentation - take

\begin{abstract}
This article aims to investigate the empirical validity of the types of lexical networks found in the cognitive literature which account for the various senses of a polysemous word by showing how each sense is an extension of another. It starts from an existing network analysis, namely Norvig \& Lakoff's [1987] analysis of the verb take, and compares its structure with data obtained from corpora and a sentence production experiment. The assessment of the validity of Norvig \& Lakoff's model is both linguistic (does the model reflect frequency as attested in naturally-occurring language?) and cognitive (does the model reflect salience in the ordinary language user's mind?). It is argued that the model does not stand up to the empirical validation proposed here, but that it may still have a role to play in a theory of polysemy.
\end{abstract}

Keywords: polysemy - lexical network - empirical validation - corpus - experimentation take

\footnotetext{
${ }^{10}$ FNRS - Université catholique de Louvain, Gaetanelle.Gilquin@uclouvain.be
} 


\section{Introduction}

It is common practice, within the framework of cognitive linguistics, to organise the different senses of a polysemous word in the form of a lexical network (also called "radial network"), with some basic, prototypical sense in the centre and increasingly peripheral senses as one moves further from the centre (see Brugman \& Lakoff [1988]). Typically, networks are established with no empirical evidence, relying on what Sandra \& Rice [1995: 94] refer to as "linguists' unshakeable confidence in their introspections". This article focuses on the highly-polysemous verb take and sets out to investigate the empirical validity of its lexical network as described in the cognitive literature, and more particularly in Norvig \& Lakoff [1987], by comparing it with (i) a network established on the basis of corpus data and reflecting linguistic frequency and (ii) a network established on the basis of experimental data and reflecting cognitive salience. It also briefly deals with the place of each of these three models in a theory of polysemy.

The article starts, in Sections 2 and 3 respectively, with some general considerations about lexical networks in cognitive linguistics and some more specific considerations about the lexical network of the verb take as described in Norvig \& Lakoff [1987]. In Section 4, this network is compared with networks obtained by means of corpus data and experimental data, according to a methodology outlined in Section 4.1. The differences and similarities between the three models (Norvig \& Lakoff's intuitive model and the corpus-based and experimental models) are discussed in Section 5, which also shows that each of the models has its relevance and may be useful for different purposes. Section 6 concludes the article.

\section{Lexical networks in cognitive linguistics}

Traditionally, categories were defined according to a number of necessary and sufficient conditions. When an element displayed these conditions, it was considered a member of the category, on a par with the other members. Work in the field of psychology, however, and in particular work carried out by Eleanor Rosch, revealed that not all members of a category have an equal status and that some are more representative of the category than others. ${ }^{11}$ This was shown to be true of many linguistic categories too (e.g. Taylor [2003]), including categories bringing together the different senses of a polysemous word. Thus, some senses of a polysemous word are claimed to be more central, or more "prototypical" than others. This organisation around prototypes has led to a representation of polysemous words in the form of lexical networks, with the most representative sense (the "prototype") at the centre and the other senses radiating from it. The different meanings of prepositions, in particular, have often been represented by means of such networks. ${ }^{12}$

Most of the time, lexical networks are established on the basis of intuition. ${ }^{13}$ Linguists identify what they consider to be the central sense of the word, and they then structure the other senses in such a way that each sense is an extension of another. As underlined by Sandra \& Rice [1995: 90], however, "there is a lot of vagueness regarding the nature of the represented reality, at both the linguistic and cognitive levels". It is the aim of this study to

\footnotetext{
${ }^{11}$ See, among others, Rosch [1978].

${ }^{12}$ For illustrations, see Brugman [1981], Lakoff [1987: 436], Dirven [1993] or Evans \& Tyler [2001].

${ }^{13}$ Some exceptions are Rice [1996], who attempts to sketch a lexical network of several prepositions on the basis of experiments, and Gries [2006], who shows how corpus data can be used to arrange the different senses of the verb run into a network.
} 
test the linguistic and cognitive validity of a lexical network against empirical data. Linguistic validity will be tested by means of frequency as attested in corpora, while cognitive validity will be tested by means of a sentence production experiment designed to elicit the most salient sense of the word represented in the lexical network. The rationale behind this choice of empirical data has to do with the centre of the network, which, as we saw above, arguably corresponds to the "prototype". Prototypicality has been defined in many ways, both in psychology and linguistics. ${ }^{14}$ For linguistic categories, it has been equated, among others, with high frequency (see for example Stubbs [2004]) and with salience (Radden [1992: 519-520] defines the prototype as "the best, clearest and most salient exemplar among the members of a category"). It is therefore reasonable to assume that lexical networks are organised in such a way that they reflect higher frequency and/or greater salience the more we move towards the centre. Corpora and experiments make it possible to study these two aspects. The network that will be investigated here is that of the verb take as described in Norvig \& Lakoff [1987]. This network is presented in the next section.

\section{The lexical network of the verb take}

Norvig \& Lakoff [1987] make a distinction between seven senses of take, illustrated by the following sentences (Norvig \& Lakoff's examples):
(1) John took the book from Mary.
(2) John took the book to Mary.
(3) John took the book to Chicago.
(4) John took a punch at Harry.
(5) John took a punch from Harry.
(6) John took Mary to the theater.
(7) John took a whiff of the coffee.

They also draw a list of semantic roles occurring in the various senses of take, reproduced in Table 1 below. The sense of take that is claimed to be central is the sense of "grabbing" (see example [1]), according to which an agent moves a patient along a path from the origin to the destination (using an instrument), with the (typical) result that the agent actually receives the patient. A number of conditions have to be fulfilled for this sense to be generated. Before the act, the recipient must be at the destination, the patient must be at the origin, the origin must be different from the destination, the source must be different from the recipient, and the agent must also play the role of the recipient. During the act, the agent must physically control the patient. By default, the agent is human, the patient is a small, light-weight physical object that is easily manipulated and within grasping distance of the agent, the instrument is the agent's arm and hand, the origin is near the agent, and the destination is at the agent's body.

\footnotetext{
${ }^{14}$ See Gilquin [forthcoming a] for an overview of the definitions found in linguistics.
} 
Participants:

$$
\begin{aligned}
& \text { A agent: active actor or causer of an action } \\
& \text { S source: initially has the patient } \\
& \mathrm{R} \text { recipient: receives the patient } \\
& \mathrm{P} \text { patient: object acted upon or affected by the agent } \\
& \text { I instrument: used to transport the patient }
\end{aligned}
$$

\section{Table 1. Semantic roles with take (Norvig \& Lakoff [1987: 198])}

From this sense of grabbing (take-1), Norvig \& Lakoff argue, all the other senses of take may be derived most economically through minimal variation links. Thus, take-2, illustrated by sentence (2) above, is a minimal variant of take- 1 in that the agent here is not the recipient. As a consequence, while the agent in take- 1 need not be moving, since it is the recipient, the agent in take-2 must move to the recipient so that the recipient may receive the patient. Take3 , exemplified in (3), differs from take-2 in terms of "profiling", that is, which elements are foregrounded or backgrounded by the verb. In take-2 the participants (source and recipient) are foregrounded (or "profiled") and the settings (origin and destination) are backgrounded, whereas in take-3 it is the settings that are foregrounded (cf. to Chicago in [3]). These three senses represent a first "meaning chain" (Taylor [2003: 110]), with take-3 being linked to take-2, itself linked to take-1.

Take-4 (cf. example [4] above), like take-3, may be linked to take-2. Take-4 is a metaphorical extension of take-2, the metaphor being that applying force is transferring an object. In other words, instead of delivering a small, light-weight physical object to the patient, the agent delivers a quick, forceful action. In take-5, unlike take-4, it is the result that is profiled. Consequently, the recipient, who is also profiled, becomes the subject of the sentence, as illustrated by (5).

Take- 6 is to be linked to take-3, the minimal difference being that take- 6 includes the socalled "Going-to-D Schema", according to which going to an destination, in this case a public establishment, stands metonymically for doing an activity that is conventionally associated with the public establishment (in example [6], going to the theatre stands for attending a theatrical play). The activity should be recreational and the patient should be human. At the end of the process, the agent does not "possess" the patient, but remains in charge of it.

Finally, take-7 is directly linked to the central sense of take-1, through the metaphor of "perceiving is receiving". The patient here is not a physical object, but a sense impression ("glance", "look", "glimpse", "taste", "sniff", or "whiff” in example [7]).

These seven senses of take and their relations to each other may be represented by the network in Figure 1, taken from Norvig \& Lakoff [1987: 205]. The figure also indicates the types of links found between the senses, namely semantic role differentiation (SR), profile shift $(\mathrm{P})$, metaphor $(\mathrm{M})$ or frame addition $(\mathrm{F})$. 


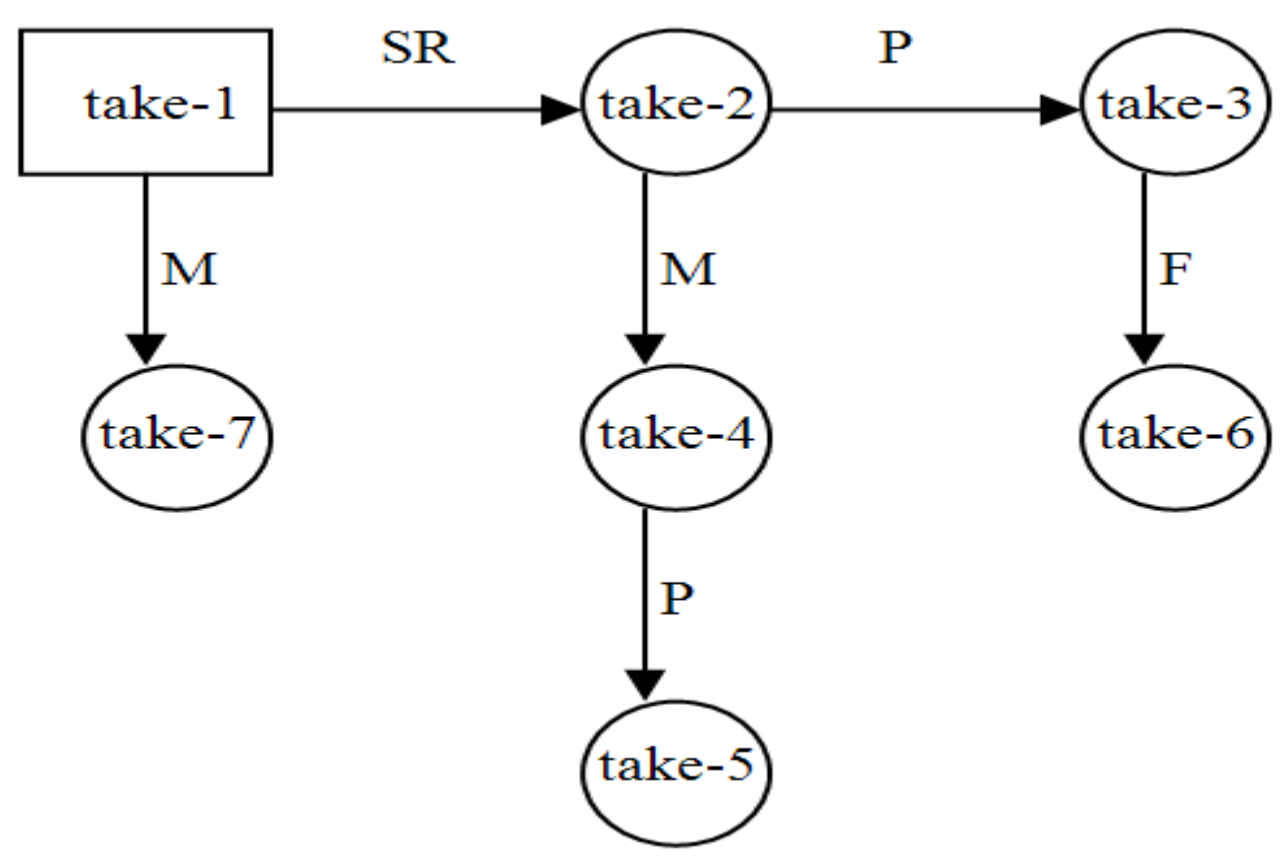

Figure 1. Schematic representation of the network of take in Norvig \& Lakoff [1987: 205]

While Norvig \& Lakoff do not make this explicit, it is quite obvious that the way they have established this network is by means of their own intuition, simply by studying the meaning variations between the different senses. When presenting the central sense of take, the sense of grabbing, they express this as a hypothesis ("what we hypothesize to be the central sense of take", Norvig \& Lakoff [1987: 198]; emphasis added), claiming that with this sense at the centre, "the other senses of take can be represented most economically in terms of minimal variation links" [ibid.]. And although they add that "speakers intuitively judge this sense to be the most basic, and dictionaries reflect this judgment" [ibid.], they do not offer any evidence for this. This intuitive approach is even clearer if we consider an earlier paper by one of the authors (Norvig [1986]), where it is argued that the "grabbing" sense of take "would be learned first as a child, and would be most likely elicited from subjects as the naive definition of take" (emphasis added). ${ }^{15}$ Admittedly, at the end of the paper, Norvig refers to what looks like corpus data, but he does not provide any results which would suggest, say, that the sense of "grabbing" is the one that is found most often in the corpus.

The network proposed by Norvig \& Lakoff [1987] and the description they give of the links between the different senses of take are convincing and intuitively appealing. The centrality of the sense of "grabbing" will also probably "make sense" to many people, and is indeed reflected in many dictionaries. ${ }^{16}$ The question, however, is whether such a model reflects any sort of reality in terms of language usage and/or mental representation. This is what we will check in the next section, by investigating corpus data (linguistic validation) and experimental data (cognitive validation).

\footnotetext{
${ }^{15}$ It should be noted that the semantic classification proposed in Norvig [1986] is slightly different from that in Norvig \& Lakoff [1987] and also includes more senses, but the prototypical sense is the same in the two papers.

${ }^{16}$ But not all of them. Thus, both the Longman Dictionary of Contemporary English [Summers 1995] and the Macmillan English Dictionary for Advanced Learners [Rundell 2007] start the entry of the verb take with the "move" sense. The sense of "grabbing" only comes later (in fifth position in the Longman dictionary and in seventh position in the Macmillan dictionary).
} 


\section{Empirical validation of the lexical network of take}

\subsection{Data and methodology}

The data for the linguistic validation of Norvig \& Lakoff's [1987] take-network were taken from two corpora, namely the Frown corpus (1999) for written language and the Switchboard corpus (1993) for spoken language. Both corpora represent American English as used in the 1990s. One thousand occurrences of the lemma take were randomly extracted from each of the corpora and the occurrences corresponding to one of the senses distinguished by Norvig \& Lakoff were manually selected. This process made it possible to obtain information about the relative frequency of the senses of take.

For the cognitive validation of Norvig \& Lakoff's [1987] proposed network, an experiment was designed in order to measure the degree of salience of the various senses of take. The experiment took the form of an online sentence production test, implemented by means of the software WebExpl (Keller et al. [1998]), and including a total of twenty word stimuli, among which the verb take. ${ }^{17}$ The words were presented on the screen one at a time and in random order, and the subjects were simply instructed to type in, for each of the words, the very first sentence they could think of containing this word. Forty native speakers of American English took part in the experiment. The sentences they produced for the verb take were isolated and the sentences corresponding to one of the senses identified by Norvig \& Lakoff [1987] formed the basis of the analysis. The assumption was that the more often a sense was produced in the experiment as a first-come-to-mind example of the word, the more cognitively salient this sense was.

\subsection{Sense distinction}

Although the aim of this article is not to discuss the validity of Norvig \& Lakoff's sense distinction, which will be assumed as a starting point in what follows, a few comments are nonetheless in order. First, the senses as they are described in Norvig \& Lakoff [1987] are very specific - too specific, in fact, to make an empirical validation possible (or at least worthwhile). Thus, take-4 is said to involve "a quick, forceful action" [ibid. 201], as in "take a punch at someone". However, very few nouns can actually take the place of "punch" with this meaning and it is probably not a coincidence that Norvig \& Lakoff do not cite any others. ${ }^{18}$ For this reason, any type of action was accepted in this study for take-4, making the metaphor that "applying force is transferring an object" slightly more general. The sense thus became roughly equivalent to the so-called delexical, or light-verb sense, ${ }^{19}$ including cases such as "take action against", "take a picture of", or even "take a walk", where the action does not affect a patient different from the agent. Similarly, physical objects other than small, lightweight objects were taken into account for take-1, and animate patients were included for

\footnotetext{
${ }^{17}$ The word stimuli included high-frequency verbs (among which take was presented twice to the participants), as well as some grammatical words.

${ }^{18}$ Norvig [1986], however, gives the example of "whip", and the Frown corpus contains another example: Granted, it was used quite cleverly by Ronald Reagan, who managed to be charmingly self-deprecating while he took a slap at Bill Clinton.

${ }^{19}$ A "light verb construction" is a construction in which the verb has little or no semantic content of its own, and the verbal meaning is expressed by the noun phrase accompanying it (Trask [1993: 160-161]).
} 
take-3 (following Norvig [1989], who claims that "John took the book to Chicago" and "John took Mary to class" represent the same sense). Even so, it should be noted that the seven senses proposed by Norvig \& Lakoff [1987] do not cover all the uses of take as exemplified in the data collected. As will appear from Tables 2 and 3, on average no more than $40 \%$ of the data are covered, a score which falls under the $30 \%$ for the written corpus data. Some of the senses which are not included in Norvig \& Lakoff's classification but which appear in the data are shown in the following sentences:

(8) The cyclists contacted the Cook County Forest Preserve District with the idea of saving remnants of Illinois prairie with volunteer labor. The idea took. (Frown)

(9) But, you know, you, you get specialized education now, for instance, take computer science. (Switchboard)

(10) It will only take a minute to brush my teeth. (Experiment)

A second remark is that some senses are very close to each other and may not actually be distinguished in ordinary speakers' mental representations. ${ }^{20}$ This is particularly striking in the case of take-2 (John took the book to Mary), take-3 (John took the book to Chicago) and take6 (John took Mary to the theatre), all of which entail movement on the part of the agent and may thus roughly be described as expressing the sense of "moving". ${ }^{21}$ As already suggested, the senses distinguished by Norvig \& Lakoff [1987] will be taken for granted here. This, however, should not be taken to mean that any cognitive or linguistic reality is recognised to this sense distinction. This is a matter for empirical verification, which would involve a corpus analysis and an experimental design different from those used here. ${ }^{22}$

\subsection{Corpus-based validation}

Each of the senses proposed by Norvig \& Lakoff [1987] was identified in a collection of 2,000 corpus-extracted sentences, 1,000 from written English (Frown) and 1,000 from spoken English (Switchboard). Table 1 gives the results of this analysis, both for writing and speech individually, and for the two corpora taken together.

\begin{tabular}{|l|r|r|r|}
\hline & Writing (\%) & Speech (\%) & \multicolumn{1}{c|}{ All (\%) } \\
\hline Take-1 & 1.4 & 3.6 & 2.50 \\
\hline Take-2 & 0.5 & 0.4 & 0.45 \\
\hline Take-3 & 7.8 & 17.2 & 12.50 \\
\hline Take-4 & 12.6 & 17.6 & 15.10 \\
\hline Take-5 & 3.7 & 1.0 & 2.35 \\
\hline Take-6 & 0.2 & 0.1 & 0.15 \\
\hline Take-7 & 1.8 & 1.0 & 1.40 \\
\hline
\end{tabular}

\footnotetext{
${ }^{20}$ See also Rice [1996: 143], who refers to the "abundance of fine-grained distinctions" in lexical networks and to the risk of these networks "[collapsing] under their own weight".

${ }^{21}$ The Longman Dictionary of Contemporary English [Summers 1995], for instance, has one single entry for these three senses.

${ }^{22}$ See Sandra \& Rice [1995] for an attempt to check whether the fine-grained distinctions made in prepositional network analyses are also made at the level of mental representation.
} 


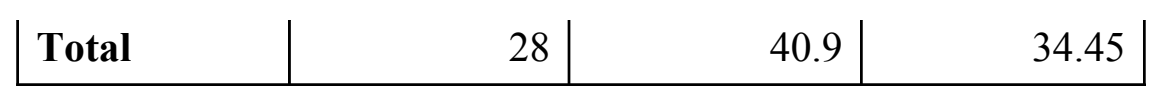

Table 2. Proportion of Norvig \& Lakoff's [1987] senses in the corpora

Let us first deal with the most "central" sense of take. While, according to Norvig \& Lakoff, the most central sense is that of "grabbing" (take-1), this sense accounts for a rather small proportion of the corpus data: $1.4 \%$ in the written corpus and $3.6 \%$ in the spoken corpus (see example [11]). The most frequent sense in the corpus data, regardless of medium, is take4, i.e. "take action (at patient)", with an average of $15.1 \%$. This sense is exemplified by (12) and (13). It thus appears that, from the point of view of usage frequency, it is not the sense of "grabbing" that is most central, but the much more abstract sense of "doing" ("taking action").

(11) I just took this Amish bread out of the oven, man, it's going to be good. (Switchboard)

(12) Meanwhile, steps were taken in Europe by the European Economic Community to change existing laws that prohibited the patenting of selectively bred plant and animal varieties so that all genetically engineered life forms might be patented. (Frown)

(13) I'm tired, I take a nap, whatever. (Switchboard)

Another sense that is quite common in the corpus data is take-3, paraphrased in Norvig \& Lakoff [1987] as "take patient to destination", and illustrated by (14) for inanimate patients and (15) for animate patients. In writing, it represents a proportion of $7.8 \%$ and in speech, its percentage is just a little lower than that of the most frequent sense of "taking action", with $17.2 \%$.

(14) It may sound like the modern-day equivalent of taking coals to Newcastle, but shipping sushi to Osaka has much to recommend it. (Frown)

(15) Fifty years later, he was taking my friend Elizabeth Hardwick to the Rainbow Room, still up to his old tricks. (Frown)

The other senses of take, namely take-2 ("take patient to recipient"), take-5 ("take action from agent"), take-6 ("take to the movies") and take-7 ("take a glance at") are all present in the (written and spoken) corpus data, as appears from examples (16) to (19), but in very small proportions, ranging from $0.15 \%$ to $2.35 \%$ overall.

(16) I said basically I built it myself, when I got to a certain point I took it to a TI engineer. (Switchboard)

(17) I really would prefer the Volvo, I think, jus-, I know it's older than the Regency but, you know, they're built of that unibody steel construction and it would take a hit fairly well. (Switchboard)

(18) I took my kids to see A Hundred and One Dalmatians. (Switchboard)

(19) Problems can be solved fairly simply by taking a good hard look around the plant. (Frown)

Note that frequency as attested in naturally-occurring language does not allow for a network representation like that obtained by Norvig \& Lakoff by means of intuition, with one sense derived from another. Rather, the results of the corpus analysis form a scale, where each 
sense is more frequent than the preceding one. Yet, it is possible to group the senses into clusters, according to their frequency in the corpora, so that the structure comes closer to the structure of the lexical network proposed by Norvig \& Lakoff. Thus, for take, one may draw a network with three levels of frequency, ${ }^{23}$ namely a level with the most frequent sense, take-4, a level with take-3, which is slightly less common in the corpus, and a third level, more peripheral, comprising the least frequent senses of take, viz. take-1, take-2, take-5, take- 6 and take-7. This may be schematically represented as in Figure 2.

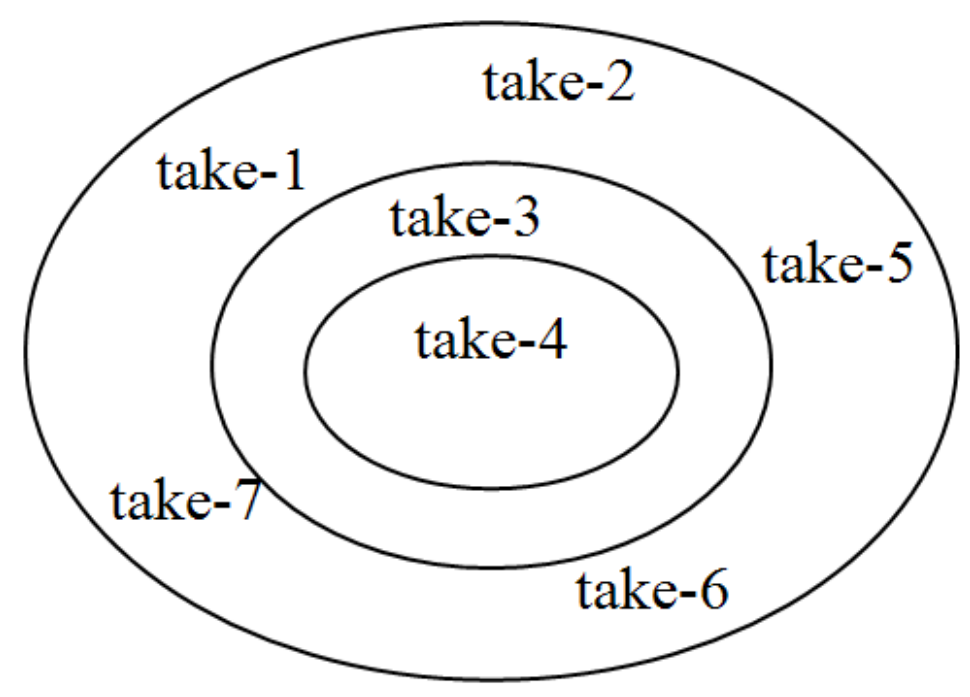

Figure 2. Corpus-based network of take

\subsection{Experimental validation}

In an attempt to investigate the cognitive reality of the network structure proposed by Norvig \& Lakoff [1987], a sentence production experiment was carried out, whose results for take can be found in Table 3. The figures represent the proportions of each of Norvig \& Lakoff's senses as identified in the first sentence produced by the participants when the word take was presented to them.

\begin{tabular}{|l|r|}
\hline & \multicolumn{1}{|c|}{ SPE (\%) } \\
\hline Take-1 & 10.0 \\
\hline Take-2 & 0.0 \\
\hline Take-3 & 20.0 \\
\hline Take-4 & 7.5 \\
\hline Take-5 & 0.0 \\
\hline Take-6 & 2.5 \\
\hline Take-7 & 0.0 \\
\hline
\end{tabular}

\footnotetext{
${ }^{23}$ Note that the division into three levels is not based on any statistical calculation, but on a rough and ready evaluation of the way the frequencies cluster together. Despite the closeness in frequency between take- 4 and take-3, the two senses were placed on separate levels so as to make the most "central" sense more apparent.
} 


\section{\begin{tabular}{|l|r|} 
Total & 40.0 \\
\hline
\end{tabular}}

\section{Table 3. Proportion of Norvig \& Lakoff's [1987] senses in the sentence production experiment}

The results suggest that the most salient sense of take (with 20\%) is take-3, as shown in (20) and (21), two of the sentences produced by the subjects for this sense. Take-3 may thus be considered central from a cognitive perspective.

\section{(20) Take this letter to the post office please. (Experiment) \\ (21) I will take you home. (Experiment)}

Next comes the sense of take-1 ("grab"), which accounts for $10 \%$ of the experimental data, followed by take-4 ("take action at patient"), which accounts for $7.5 \%$, and finally take6 ("take to the movies"), with a small proportion of $2.5 \%$. These senses are illustrated by the following sentences:
(22) Try not to take too many cookies. (Experiment)
(23) I will take a shower. (Experiment)
(24) He wanted to take me to a baseball game. (Experiment)

The remaining senses, namely take-2 ("take patient to recipient"), take-5 ("take action from agent") and take-7 ("take a glance at"), do not occur at all in the participants' answers.

Like the corpus data, the experimental data cannot be represented by means of meaning chains, where one sense is derived from another, as is the case in Norvig \& Lakoff's network. However, this structure can be approximated by grouping the senses according to their degree of salience. Four clusters seem to emerge from Table 3, namely one central level with take-3 (20\%), a second level with take-1 and take-4 (10\% and 7.5\%, respectively), a third level with take-6 (2.5\%), and a fourth level, with senses that belong to take but have little or no cognitive salience, since they were not produced by the participants when they first saw the word take on their screens (take-2, take-5 and take-7). This four-level structure may be represented by Figure 3, where the shading indicates non-salient senses. 


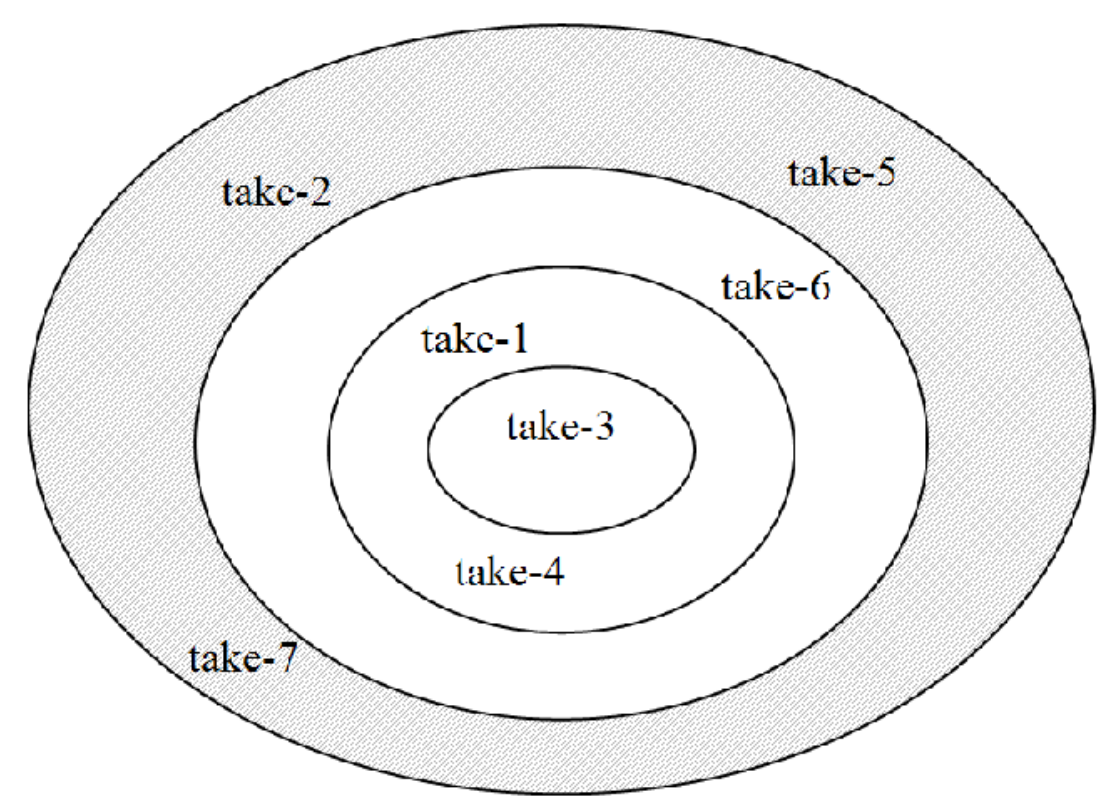

Figure 3. Experimental network of take

Interestingly, the level-2 status of take- 1 is confirmed if we consider other results from the experiment. As pointed out in note 7, the stimulus take was presented twice to the participants, which means that they had to produce two sentences for this verb. One may assume that the first sentence produced by the subjects represents the most salient sense in their minds, whereas the second sentence represents a slightly less salient sense. If we exclude repetitions (some participants produced the same sentence for each of the two occurrences of the stimulus), the results are as shown in Table 4. It turns out that the most commonly produced sense for the second occurrence of take as a stimulus is take-1 (47.1\%), which suggests that this sense comes second in terms of cognitive salience. Note also that the senses which were the least salient in the responses to the first occurrence of the stimulus (levels 3 and 4 in Figure 3), viz. take-2 ("take patient to recipient"), take-5 ("take action from agent"), take-6 ("take to the movies") and take-7 ("take a glance at"), are also the least salient in the responses to the second occurrence of the stimulus (5.9\% for take- 2 and $0 \%$ for the others).

\begin{tabular}{|l|r|}
\hline & SPE_2 (\%) \\
\hline Take-1 & 47.1 \\
\hline Take-2 & 5.9 \\
\hline Take-3 & 17.6 \\
\hline Take-4 & 11.8 \\
\hline Take-5 & 0.0 \\
\hline Take-6 & 0.0 \\
\hline Take-7 & 0.0 \\
\hline Total & 82.4 \\
\hline
\end{tabular}

Table 4. Proportion of Norvig \& Lakoff's [1987] senses in the sentence production experiment (second occurrence of the stimulus) 


\section{Comparison of the results and discussion}

Section 3 presented the lexical network of take as (intuitively) described by Norvig \& Lakoff [1987], while in Sections 4.3 and 4.4 networks of the verb were drawn on the basis of corpus data and experimental data. Before discussing the differences and similarities between these three networks, it is necessary to somewhat reinterpret Norvig \& Lakoff's network so as to make it more comparable to the two networks established empirically.

Norvig \& Lakoff [1987] posit that take-1 is the central sense of take. It thus corresponds to what we have referred to as the level-1 sense. In order to identify the other levels, the following line of reasoning was applied: a sense that is directly derived from take- 1 is more central than one that is derived from another sense, which itself is derived from take- 1 . The level of a sense is therefore considered here to be dependent on the number of links that separate it from the centre of the network, whatever the nature of the link (semantic role differentiation, profile shift, metaphor or frame addition). Thus, take-2 belongs to level 2, because it is directly derived from take-1 (one link). Take-3, on the other hand, is not directly derived from take-1, but is derived from take-2, which itself is derived from take-1. Because two links separate take-3 from take-1, it is considered to belong to level 3. As for take-6, it is separated from take- 1 by three links (from take- 1 to take-2, from take- 2 to take- 3 and from take-3 to take-6), which makes it a level-4 sense. The distribution of Norvig \& Lakoff's seven senses according to levels is shown in Table 5, which also contains the results of the corpus analysis and the sentence production experiment in terms of levels. The shading of the level-4 box in the experimental data signals that the senses were not found in the data, and the bold print indicates the senses which belong to the same level across networks.

\begin{tabular}{|l|c|c|c|}
\hline & N \& L [1987] & Corpus data & Experimental data \\
\hline Level 1 & take-1 & take-4 & take-3 \\
\hline Level 2 & take-2 & take-3 & take-1 \\
& take-7 & & take-4 \\
\hline Level 3 & take-3 & take-1 & take-6 \\
& take-4 & take-2 & \\
& & take-5 & \\
& & take-6 & \\
& & take-7 & \\
& take-5 & & take-2 \\
& take-6 & & take-5 \\
& & & take-7 \\
\hline
\end{tabular}

Table 5. Summary of the network structure of take in Norvig \& Lakoff [1987], and in the corpus and experimental data

What is striking in the above table is the lack of correspondence between the three models. Only two senses are shared by a level in two models, namely take- 6 (in level 3 of the 
corpus data and the experimental data) and take-5 (in level 4 of Norvig \& Lakoff's model and the experimental data), and of these two, one (take-5) actually belongs to the level which is not represented in the experimental data (also valid for the responses to the second occurrence of the stimulus). The remaining senses all differ in level across networks.

Particularly interesting is the first level of the networks, which one may expect to be similar across models, since they all somehow qualify for the status of "prototype". Although Norvig \& Lakoff [1987] do not use this term to describe take-1, Norvig [1986] in a previous version of the model does, and lexical networks in the cognitive literature are typically said to centre around a prototype (cf. Rice [1996: 136]). As we saw above, highest frequency as attested in corpus data has been equated with prototypicality (see Stubbs [2004]). As for the test consisting in asking for the first-come-to-mind item, it is a standard test to uncover the prototype of a category (cf. Ungerer \& Schmid [1996: 39]). ${ }^{24}$ Yet, the three models turn out to produce different results even at the first level of the network. While Norvig \& Lakoff [1987] suggest that the sense of "grabbing" is in the centre of the network, the corpus analysis places the sense of "taking action" in the middle, and the experiment, the sense of "taking patient to destination". This contrast is illustrated by the following three sentences, which represent the "prototypes" of each of the three models:

(25) The baby took the toy from its mother. (Norvig \& Lakoff [1987: 199])

(26) I took a picture of her and that was all it lasted for. (Switchboard)

Take me to the moon, Alice. (Experiment)

The other levels display similar discrepancies across models, with, for example, a level 2 made up of take-2 ("take patient to recipient") and take-7 ("take a glance at") in Norvig \& Lakoff, take-3 ("take patient to destination") in the corpus data, and take-1 ("grab") and take4 ("take action at patient") in the experimental data. Notice how take-2 and take-7, which are considered as relatively central by Norvig \& Lakoff, are among the least frequent senses in the corpus data (an overall $0.45 \%$ and $1.40 \%$, respectively) and are never produced by the subjects in the online experiment (at least, not as a response to the first occurrence of the stimulus).

The dissimilarity between the three models calls for an explanation. While the divergences between the corpus data and the experimental data may be explained by the existence of different principles governing the two types of data, ${ }^{25}$ the discrepancy between the theoretical model proposed by Norvig \& Lakoff [1987] and the empirical data seems to challenge the validity of Norvig \& Lakoff's lexical network of take, which appears to have no linguistic reality in terms of frequency and no cognitive reality in terms of salience. One may argue that this is not the aim pursued by Norvig \& Lakoff, who simply want to "state generalizations governing the relations among the senses" [ibid. 198]. As Gibbs \& Matlock [2001: 214] point out,

[Some] cognitive linguists view their proposals about polysemy, for instance on lexical networks, as representational schemes of the diachronic and synchronic relations underlying polysemous words and, consequently, make no claims about mental representations or whether these schemes are used in online linguistic processing.

\footnotetext{
${ }^{24}$ See also the sentence generation task described in Rice [1996: 148-152] and Cuyckens et al. [1997: 42-43].

${ }^{25}$ See Gilquin [forthcoming b].
} 
While Norvig [1986] goes some way towards making such a claim, by suggesting that the sense of "grabbing" "would be most likely elicited from subjects as the naive definition of take", Norvig \& Lakoff [1987] make no such claims. Nor do they make any claims about the predictability of their model in terms of corpus-attested frequency. However, this may seem quite unexpected (and indeed, disappointing), coming from a theoretical framework, cognitive linguistics, which has psychological reality as one of its goals (Langacker [1987: 56]) and a usage-based approach as one of its basic tenets [ibid. 46]. Surely, as a cognitive linguist, one must, in Cuyckens et al.'s [1997: 51] words, "commit [oneself] to at least some psycholinguistically relevant claims".

This does not mean that the (intuition-based) network proposed by Norvig \& Lakoff and other similar networks found in the cognitive literature should be thrown away. Provided we can show that the network, with its sense distinction and meaning chains, makes sense to (most) language users and does not merely mirror the linguist's mind, as Sandra \& Rice [1995] put it, it may still be relevant, as long as one bears in mind that it does not reflect degrees of salience or frequency, but simply highlights minimal variation between interrelated senses. In particular, it constitutes a neat way of presenting the different senses of a polysemous word in relation to each other (the corpus-based and experimental networks proposed above, by contrast, appear to be much less logical, or "motivated"). Such a presentation may have useful applications in fields such as lexicography or foreign language teaching. ${ }^{26}$ Norvig \& Lakoff [1987] also demonstrate how an analysis such as theirs makes it possible to explain certain facts of language, for example that the acts of perceiving with take are typically short ones (cf. take a peek or take a whiff), which is to be related to the default value of the patient in take-1, a small, light-weight physical object, and to the mapping, between the two linked senses, of the size of the physical object onto the duration of the action. The corpus-based network, on the other hand, tells us something about language as it is used in natural settings. It mainly has a descriptive function, but one which may prove very useful in natural language processing (e.g. for the semantic annotation of corpora), or to inform the more advanced stages of foreign language teaching, by showing learners what the most frequent usage of a polysemous word is (even if it is a more abstract and perhaps idiomatic usage) and by providing them with authentic examples of this and other uses of the word. The experimental network, finally, may serve as a first step (necessarily to be supplemented by data from other experiments) in studying ordinary speakers' mental representations for polysemous words and coming to a better understanding of polysemy as a psycholinguistic phenomenon. In sum, each network has its relevance for a theory of polysemy, but should be used for different purposes and with full awareness of its possibilities and limitations.

\section{Conclusion}

In this article, we started from a network analysis of the polysemous verb take found in Norvig \& Lakoff [1987], with the aim of assessing its linguistic and cognitive validity by means of empirical evidence. While Norvig \& Lakoff's lexical network is in all likelihood based on the authors' intuitions, the two alternative networks proposed here rely on corpus data (to measure the linguistic frequency of the different senses identified by Norvig \& Lakoff) and on data from a sentence production experiment (to measure the cognitive salience

\footnotetext{
${ }^{26}$ See for example Verspoor \& Lowie [2003] on the lexical acquisition of polysemous words and the beneficial effect of a "core meaning approach".
} 
of the senses). It turned out from the comparison of the three networks that Norvig \& Lakoff's model does not stand up to the type of empirical validation it was submitted to: the different levels of "centrality" posited by Norvig \& Lakoff correspond neither to degrees of frequency in authentic language, nor to degrees of salience in the ordinary speaker's mind. Yet, it was shown that lexical networks such as Norvig \& Lakoff's may still be useful, provided one is fully aware of what they can and cannot do.

It should be emphasised that Norvig \& Lakoff's model was only submitted to two types of evaluation. These two types of evaluation may not be the best ones to answer our research question. Gibbs \& Matlock [1999], for example, warn against viewing psycholinguistic evidence as a direct and necessarily accurate reflection of language users' mental representations. Moreover, as suggested by Frisson et al. [1996: 643], there are "various levels at which network models of lexical processing can or should be assessed". The fact that the lexical network proposed by Norvig \& Lakoff reflects neither usage frequency nor cognitive salience does not mean that it lacks any reality. Other factors should be investigated, such as historical development, order of acquisition or comprehension processes (as opposed to the productive approach that was adopted here). What we would ultimately need is, as Rice [1996: 162] puts it, "converging evidence from multiple sources". Only when several sources have been examined and each has been demonstrated to differ from the network under study in fundamental ways will we be able to deny any empirical validity to the network. Until then, we will have to give "armchair linguists" (as Fillmore [1992] calls them) the benefit of the doubt and admit that at some as yet uncovered level, their models may have empirical validity and mirror something else than just their (undeniably sharp) minds.

\section{References}

Brugman Claudia, 1981, The Story of Over, M.A. Thesis, University of California, Berkeley (reproduced by the Indiana University Linguistics Club).

Brugman Claudia and Lakoff George, 1988, "Cognitive topology and lexical networks", in Small Steven L., Cottrell Garrison W. and Tanenhaus Michael K. (Eds), Lexical Ambiguity Resolution, San Mateo, CA, Morgan Kaufman, 477-508.

CuYckens Hubert, SAndra Dominiek and Rice Sally, 1997, "Towards an empirical lexical semantics", in Smieja Birgit and Tasch Mieke (Eds) Human Contact Through Language and Linguistics, Frankfurt am Main, Peter Lang, 35-54.

Dirven René, 1993, "Dividing up physical and mental space into conceptual categories by means of English prepositions", in Zelinsky-Wibbelt Cornelia (Ed.), The Semantics of Prepositions: From Mental Processing to Natural Language Processing, Berlin, Mouton de Gruyter, 73-97.

Evans Vyvyan and Tyler Andrea, 2001, "Reconsidering prepositional polysemy networks: the case of over", Language 77.4, 724-765.

Fillmore, Charles J., 1992, “Corpus linguistics' or 'Computer-aided armchair linguistics”, in Jan SVARTVIK (Ed.), Directions in Corpus Linguistics. Proceedings of Nobel Symposium 82, Stockholm, 4-8 August 1991, Berlin \& New York, Mouton de Gruyter, 35-60.

Frisson Steven, SAndra Dominiek, Brisard Frank, Cuyckens Hubert, 1996, "From one meaning to the next: the effects of polysemous relationships in lexical learning", in Pütz 
Martin and Dirven René (Eds), The Construal of Space in Language and Thought, Berlin \& New York, Mouton de Gruyter, 613-647.

FROWN (Freiburg - Brown Corpus of American English), 1999, Freiburg, Albert-LudwigsUniversität Freiburg.

Gibis Raymond W. Jr. and Матцоск Teenie, 1999, "Psycholinguistics and mental representations", Cognitive Linguistics 10.3, 263-269.

---, 2001, "Psycholinguistic perspectives on polysemy", in Cuyckens Hubert and Zawada Britta E. (Eds), Polysemy in Cognitive Linguistics, Selected Papers from the International Cognitive Linguistics Conference, Amsterdam, 1997, Amsterdam \& Philadelphia, John Benjamins Publishing Company, 213-239.

Gilquin Gaëtanelle, forthcoming a, "What You Think Ain't What You Get: highly polysemous verbs in mind and language", in Lapaire Jean-Rémi (Ed.), Grammaire et Cognition, Bordeaux, Presses Universitaires de Bordeaux.

---, forthcoming b, "Language production: a window to the mind?", in Götzsche Hans (Ed.), Proceedings of the 22nd Scandinavian Conference of Linguistics, Aalborg, Denmark, June 19-22, 2006, Cambridge, Cambridge Scholars Press.

GrIEs Stefan Th., 2006, "Corpus-based methods and cognitive semantics: the many meanings of to run", in Gries Stefan Th. and Stefanowitsch Anatol (Eds), Corpora in Cognitive Linguistics: Corpus-Based Approaches to Syntax and Lexis, Berlin \& New York, Mouton de Gruyter, 57-99.

Keller Frank, Corley Martin, Corley Steffan, Konieczny Lars and Todirascu Amalia, 1998, WebExp: A Java Toolbox for Web-Based Psychological Experiments. Technical Report HCRC/TR-99, Edinburgh, Human Communication Research Centre, University of Edinburgh. See http://www.webexp.info.

Lakoff George, 1987, Women, Fire, and Dangerous Things: What Categories Reveal about the Mind, Chicago, University of Chicago Press.

Langacker, Ronald W., 1987, Foundations of Cognitive Grammar. Vol. I. Theoretical Prerequisites, Stanford, CA, Stanford University Press.

Norvig Peter, 1986, "On defining polysemous words", in Proceedings of the Third Annual Conference on Theoretical Issues in Conceptual Information Processing, Philadelphia, PA. Slightly revised version available online at http://www.norvig.com/ticip.html (last accessed on 1 November 2007).

---, 1989, "Building a large lexicon with Lexical Network Theory", in Proceedings of the First International Language Acquisition Workshop. Available online at http://www.norvig.com/lnt.pdf (last accessed on 1 November 2007).

Norvig Peter and Lakoff George, 1987, "Taking: A study in lexical network theory", in Aske Jon, Beery Natasha, Michaelis Laura A. and Filip Hana (Eds), Proceedings of the Thirteenth Annual Meeting of the Berkeley Linguistics Society, February 14-16, 1987. General Session and Parasession on Grammar and Cognition, Berkeley, BLS, 195-206.

RADDEN Günter, 1992, “The cognitive approach to natural language”, in Pütz Martin (Ed.), Thirty Years of Linguistic Evolution. Studies in Honour of René Dirven on the Occasion of his Sixtieth Birthday, Amsterdam \& Philadelphia, John Benjamins Publishing Company, 513-541.

Rice Sally, 1996, "Prepositional prototypes", in Pütz Martin and Dirven René (Eds), The Construal of Space in Language and Thought, Berlin \& New York, Mouton de Gruyter, 135-165. 
Rosch Eleanor, 1978, "Principles of categorization", in Rosch Eleanor and Llyod Barbara B. (Eds), Cognition and Categorization, Hillsdale, N. J., Lawrence Erlbaum Associates, 27-48.

Rundell Michael (Ed.), 2007, Macmillan English Dictionary for Advanced Learners. Second Edition, Oxford: Macmillan Education.

SANDRA Dominiek and Rice Sally, 1995, "Network analyses of prepositional meaning: mirroring whose mind - the linguist's or the language user's?", Cognitive Linguistics 6.1, 89-130.

StubBs, Michael, 2004, "On very frequent phrases in English: distributions, functions and structures", Plenary lecture given at ICAME 25 (International Computer Archive of Modern and Medieval English), Verona, Italy, 19-23 May 2004.

Summers Della (Ed.), 1995, Longman Dictionary of Contemporary English. Third Edition, Harlow, Pearson Education.

SWITCHBOARD-1, Philadelphia, Linguistic Data Consortium, 1993.

TAYlor John R., 2003, Linguistic Categorization. Third Edition, Oxford, Oxford University Press.

Trask Robert L., 1993, A Dictionary of Grammatical Terms in Linguistics, London, Routledge.

Ungerer Friedrich and Schmid Hans-Jörg, 1996, An Introduction to Cognitive Linguistics, London \& New York, Longman.

Verspoor Marjolijn and LowIE Wander, 2003, "Making sense of polysemous words", Language Learning 53.3, 547-586. 